\title{
Editorials
}

\section{The Acheson report: beyond parenthood and apple pie?}

One of us was recently visited by a representative of the government of a "less developed" country, to discuss health promotion. It rapidly became-refreshinglyapparent that the government concerned was not interested in the "parenthood and apple pie" pronouncements characteristic of so many international charters and declarations about healthy public policy. Rather, it actually intended to use health promotion to significantly improve the daily lives of its people.

Heady stuff; arguably, the very stuff that the UK Labour government's reformers had in mind when developing their concept of "joined up thinking", ${ }^{2}$ appointing the first Minister for Public Health, and asking the former government chief medical officer, Sir Donald Acheson, to carry out "an independent review to identify priority areas for future policy development, which scientific and expert evidence indicates are likely to offer opportunities for Government to develop beneficial, cost effective and affordable interventions to reduce health inequalities". ${ }^{3}$

So has the Acheson report taken the UK governmentand for that matter, the international "equity community", which looks to the UK for leadership on these issuesbeyond parenthood and apple pie? The answer would seem to be a somewhat qualified affirmative one. On the positive side, its proposals build on an evidence-based review of determinants of health inequality that range from private medical practice to the European Union's Common Agricultural Policy; from decision latitude in the workplace to income distribution. At the very least this is a comprehensive, topical summary - and one in which the emphasis on academic rigour does not obscure the authors' evident concerns regarding the social injustices represented by the evidence that they review.

But, given the high expectations generated by the levels of expertise within the Acheson group and by the systematic and rigorous approach to evidence that it adopted, the report also disappoints. This is most apparent in its cursory treatment of important causes of health inequality like racism and gender role constraints (the report consistently confuses gender with sex), and its complete omission of others - such as globalisation and macroeconomic policy.

Some of this disappointment can undoubtedly be attributed to the inadequate consideration given by the report to theoretical aspects of health inequality - most obviously, its meaning and its implications for policy. There is no attempt to define either health or health inequality; nor to differentiate between inequality and inequity. While there is a section contrasting absolute and relative inequalities, no consideration is given to the key conceptual distinction between inequality and disadvantage or deprivation, and the policy implications that flow from it. In terms of making the concept of inequality operational, the report adopts Dahlgren and Whitehead's classification of the main determinants of health. ${ }^{4}$ In addition, a model showing how differential exposures that explain health inequalities interconnect "has been used to guide research". If this confused and confusing model (figure 2 in the report) did indeed guide the Acheson group's researches, it can only have distorted their discussions and conclusions.
Despite these reservations, however, much in the report deserves commendation. The 39 recommendations, if fully implemented, would represent a major shift towards a more equitable society. The Acheson group has itself prioritised, in the report's synopsis, the areas of "health inequality impact assessment" of government policy; the health of families with children; and action to reduce income inequalities and poverty. The key issue now is how fully the recommendations will be implemented. Will the evidence and its policy implications, as outlined in the report, be used to guide central government and local policy development; or will they merely provide a vocabulary for powerful political rhetoric that is not backed up by substantive action?

In addition to identifying specific priorities for action, the report proposes a generalised focusing of policy on the poorer sections of society, and an integrated approach that coordinates policies and implementation programmes. Both of these have important and far reaching implications for future public policy development.

The section of the report dealing with poverty and income clearly demonstrates the need for "joined up thinking" both within government and between government departments and local organisations. This requires not only a shared vision and common goals, but also real incentives to work together. For example, the health impact on people in poverty of improving social security benefits and increasing employment opportunities will be greatest if in addition, better opportunities are provided for the beneficiaries of these policies to spend their income in "healthier" ways - such as those resulting from improved access to healthier food and lifestyle choices.

The Acheson report clearly indicates that inward looking approaches - in which the taxation system operates in isolation from employment policies, or where urban planning is divorced from local community development-are neither tenable nor sustainable if the government is serious about its aims of tackling social cohesion and inequality. The wide range of competing agendas and budgetary constraints currently to be found at all levels makes the removal of professional, organisational and financial barriers to joint working an urgent priority for action - and one that might require the judicious use of both sticks and carrots by government.

If the Acheson report is to achieve a sustained impact that goes well beyond parenthood and apple pie, a shift away from the short-term agendas favoured by politicians will be required. In addition, the UK government will need to make explicit value judgements, where there are gaps in the evidence about the causal health impacts of social and economic factors, that public policies aimed at changing the determinants of health inequality will, in the longer term, change the lives of the UK population for the better.

ALEX SCUUTH-SAAREES

EQUAL (Equity in Health Research and Development Unit), Department of Public Health, University of Liverpool, Whelan Building, Quadrangle, Liverpool L69 3GB

Funding: none.

Conflicts of interest: none. 
1 Miller C. Foint action on health inequalities. London: Health Education Authority, 1998

2 Social Exclusion Unit. Bringing Britain together; a national strategy for neighbourhood renewal. $\mathrm{Cm}$ 4045. London: The Stationery Office, 1998.
3 Sir Donald Acheson (Chairman). Independent inquiry into inequalities in health. Report. London: The Stationery Office, 1998.

4 Dahlgren G, Whitehead M. Policies and strategies to promote social equity in health. Stockholm: Institute of Futures Studies, 1991.

\section{$\mathrm{JECH}$ and the world wide web}

Visitors to the world wide web can now access the fournal of Epidemiology and Community Health either through the BMJ Publishing Group's home page (http://www.bmjpg.com) or directly by using its individual URL (http://www.jech.com). There they will find the following:

- Current contents list for the journal

- Contents lists of previous issues

- Members of the editorial board

- Subscribers' information

- Instructions for authors

- Details of reprint services.

\section{Hotlink}

A hot link gives access to:

- BMJ Publishing Group home page

- British Medical Association website

- Online books catalogue

- BMJ Publishing Group books.

\section{Suggestions welcome}

The website is at a preliminary stage and there are plans to develop it into a more sophisticated site. Suggestions from visitors about features they would like to see are welcomed. They can be left via the opening page of the BMJ Publishing Group site or, alternatively, via the journal page, through "about this site". 